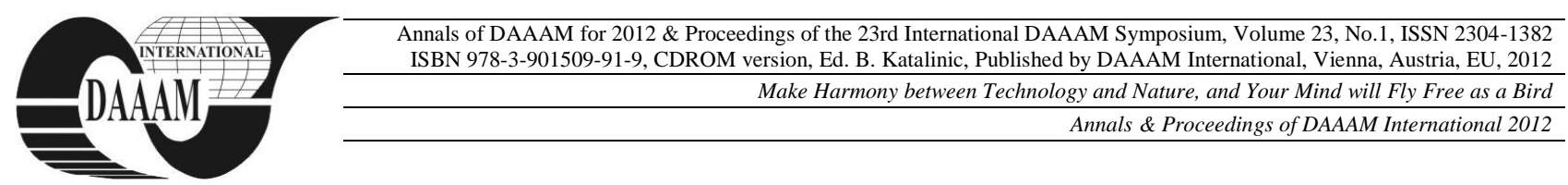

\title{
INCREASING WEAR RESISTANCE OF THE SUPERFICIAL MICROALLOYING LAYERS
}

\author{
BARHALESCU, M[ihaela] L[uminita]; SABAU, A[drian] \& OANTA, E[mil]
}

\begin{abstract}
Structuralchanges occurring in the superficial layers of samples processed through electrical sparking method has major influences for increasing the wear resistance. The paper shows some theoretical and experimental aspects with respect to superficial hardening of the grey cast irons and carbon steels. The used process for the superficial hardening allows obtaining very high hardness $(1100 H \mathrm{H})$ on the treatment surfaces, without the change of the bulk structure. The microalloying and deposition with vibrator electrode give the superficial hardening.
\end{abstract}

Keywords: Deposition, layer, discharges, hardness, wear

\section{INTRODUCTION}

The efficient and rational use of metallic materials is a problem of actual interest in most factories. The superior capitalization of metallic materials into products is obtained by application of the most efficient bulk and / or surface - thermal treatments.

In most cases, the pieces are made by carbon steel, low-alloy steel or rich-alloy steel and in some cases by irons. In order to increase the wear resistance and the hardness, major properties of pieces, these are subjected to superficial hardening treatments: thermal (superficial chilling), thermochemical treatments.

This paper presents a theoretical and experimental evaluation, with respect to the superficial hardening of the grey cast irons and carbon steels. The experiments on some parts, were done for a superficial hardening in order to obtain a very high hardness $(1100 \mathrm{HV})$ on the treated surfaces, without the change of the structure, being necessary to use different processes. These research is limited to the materials used for the experiment, the dimension of the supporting pin-shoe assembly and can be applicable in specific conditions.

For the same purpose of increasing the endurance of pieces (machines organs, tools) intensely subjected to wear, in the last time a series of unconventional superficial treatments were imposed. One can remember the thermal treatments with laser beam, thermal treatments with electron beams and, last but not the least, the PVD and CVD. All these methods confer very high hardness to superficial layers, yielding to a considerable enhancement to the treated piece lifetime [3].

In important disadvantage of these treatments is the high-price since expensive installations and devices are needed. Recently, in the field of surface engineering a new kind of superficial thermal treatment of microalloying and spark deposition was imposed. Spark microalloying method is based on the material transfer effect from electrode to the surface of the treated piece during the electrical discharge in the gaseous environment between electrode and piece. The basic requirement is the electrical conductivity of the piece and electrode [3].

After being subjected to such a treatment, the piece surface will be covered with a layer made by electrode material, named white layer, under which is a diffusion zone formed by the basis material in which the electrode material has diffused.

The processes, which take place in the piece superficial layer during the treatment, are:

- the acquiring of a possible layer of white cast iron on the grey cast iron pieces, on which the deposition with hard carbides is achieved;

- the microalloying by combining the electrode elements with melted metal and basic material.

The currently obtained layer thickness are up to 50 $\mu \mathrm{m}$ with a layer consistence up to $100 \%$ and roughness $\mathrm{R}_{\mathrm{a}}=3.2-14.8 \mu \mathrm{m}$

The electric spark of method basic requirement is the electrical conductivity of the piece and electrode. This fact determines the use of metals, metallic alloys, metalloceramic materials and fireproof compounds as electrodes and pieces.

The electric spark processing begins by bringing the electrode (anode) near the piece electrode (cathode), and when the distance becomes smaller than the percolation threshold, an impulse electric discharge forms which ends when the electrodes touch.

The last phase of the process begins when the pressure (given by removing the vibrating electrode) between the electrodes decreases, and ends when the electric circuit breaks off, at a distance greater than the percolation threshold (which is equal to the amplitude of vibration). Using the RC impulse generator, when the electrodes separate, an electric spark may or may not appear. Even if an electric spark appears, it will produce a negligible electrode erosion effect.

During the spark $\left(10^{-6}-10^{-3} \mathrm{~s}\right)$, at the electrodes surface, localized centers of melt and evaporation develop, leading to electrodes erosion. Due to polar effect, the predominant transfer of eroded anode material to the cathode provides the forming of the superficial layers of diffusion (alloying) and deposition (white) with well-determined properties.

After discharge, at a certain time, the anode electrode is removed from the cathode piece, switching off the electric circuit; then the process is resumed, finally 


\begin{tabular}{|c|c|c|c|c|c|c|c|}
\hline \multirow[b]{2}{*}{ No. } & \multirow[b]{2}{*}{ Samples } & \multirow{2}{*}{$\begin{array}{c}\text { Electrode } \\
\text { type }\end{array}$} & \multirow{2}{*}{$\begin{array}{c}\text { Work } \\
\text { Condition }[\mathrm{A}]\end{array}$} & \multicolumn{3}{|c|}{ Microhardness $\mathrm{HV}_{50}$} & \multirow{2}{*}{$\begin{array}{c}\text { Layer } \\
\text { thickness }[\mu \mathrm{m}]\end{array}$} \\
\hline & & & & Layer & Transition zone & Basic structure & \\
\hline \multirow[t]{2}{*}{1.} & \multirow[t]{2}{*}{ Fc 250} & WCo8 & \multirow[t]{2}{*}{1.2} & 1010 & 480 & 320 & \multirow[t]{2}{*}{30} \\
\hline & & TiCo6 & & 890 & 440 & 330 & \\
\hline \multirow[t]{2}{*}{2.} & \multirow[t]{2}{*}{ Fc 250} & WCo8 & \multirow[t]{2}{*}{2.0} & 990 & 460 & 320 & \multirow[t]{2}{*}{46} \\
\hline & & TiCo6 & & 895 & 440 & 315 & \\
\hline \multirow[t]{2}{*}{3.} & \multirow[t]{2}{*}{ Fc 250} & WCo8 & \multirow[t]{2}{*}{2.8} & 1000 & 450 & 310 & \multirow[t]{2}{*}{58} \\
\hline & & TiCo6 & & 910 & 420 & 320 & \\
\hline
\end{tabular}

Tab. 1. The samples type, the work conditions and the measured microhardness values

leading to compositional and structural changes of the superficial layer of the cathode. The characteristics of this later can vary over large limits as a function of electrodes material, environment composition between the electrodes and parameters of the impulse discharge (the discharge energy and vibration amplitude of the anode electrode).

The process of alloying and deposition by electric spark with vibrating electrode permits the modification of the dimensions and relief of the piece and tool, modification of the chemical composition, delivery state and in final treatment state ( hardening and structure and physical, chemical, mechanical and technological properties of the superficial treatment. The method can be used by hand or automatic.

Further research will be done in terms of the possibilities of obtaining metallic superficial layers with amorphous structure with high wear resistance.

\section{EXPERIMENTAL RESULTS}

The first series of experiments were done on grey cast iron samples Fc 250, subjected to superficial microalloying. We utilized electrodes of sintered tungsten and titanium carbides, used for scintillation at different work conditions (discharge current and oscillation frequency).

After the superficial treatment, the samples microhardness was determined with a PMT -3 apparatus. The samples type, the work conditions and the measured microhardness values are given in table 1.By analyzing the data from Table 1 one notices that microhardness on layer is greater than on basic structure and enhanced values are obtained using the tungsten carbide electrodes.

The structure investigations will be made with $\mathrm{X}$ rays diffraction techniques. This kind of techniques has two components, both are as important: experimental system configuration and the theoretical model for experimental data interpretation. In many case, the fine structure investigations use diffractometric technique with goniometric montage Brag - Bretano type.

$\mathrm{X}$-ray diffraction, in classic theory, means the interference between electromagnetic waves with waves of length situated within $0.5-3.0 \AA$ domain. The interference of waves is produced if they are coherent, then in one direction their phase difference is an integer (number) from $2 \pi$ radians or the wave's way difference is a number of wave lengths. This condition is known as Bragg equation law and has the expression [5]:

Where:

$$
2 \mathrm{~d}_{\mathrm{hkl}} \sin \Theta_{\mathrm{i}}=\mathrm{n} \lambda
$$

- $\mathrm{d}_{\mathrm{hkl}}$ is distance between two planes with (hkl) indexes;

- $\Theta_{\mathrm{i}}$ is diffraction angle;

- $\mathrm{N}$ is diffraction order;

- $\lambda$ is wave's length for $\mathrm{X}$ radiation.

Crystalline phases analysis using $\mathrm{X}$ - ray diffraction has the following aspects:

a. each structure phase will generate a specific diffraction specter because each has its own crystalline network.

b. geometric form and intensity of diffraction maximums depends on the structure factors and on the phase quantity which generates the maximums.

The diffractionimage of metallic sample, polyphases, will be the result of diffraction specters, produced from components phases overlap [4].

The most used method for quality structure analysis is the comparison of information between the analyzed structure extracted from sample difractogram (the image of diffraction) and well known crystalline substances, organized in data bases. Usually diffractometers are used for recording of diffraction results. The investigations for superficial layers obtained by using electrical discharge method was made with DRON 3 diffractometer which has a radiation tube with molybdenum anode, under the following working conditions: radiation Mo $\mathrm{K}_{\alpha}$, with $\lambda_{\text {Mo }}$ $=0.7107 \AA$; t the acceleration tension on the tube: $40 \mathrm{KV}$ : cathode current supply: $15 \mathrm{~mA}$; sample rotation speed: $\omega_{1}=4 \%$ min inscription band speed: $1800 \mathrm{~mm} / \mathrm{h}$; working slit: $1 \mathrm{~mm}$ and $0.5 \mathrm{~mm}$.

By using Bragg equation it was determined that the structure interplanes distances, which was generated by the diffraction maximums and the crystalline phases which compose the superficial layers were identified. The diffraction data are given in Table 2.

The difracogrames contain maxima due both to the new-formed layers $\left(\mathrm{W}_{2} \mathrm{C}, \mathrm{WC}, \mathrm{TiC}\right)$ and to the basic structure $\left(\mathrm{F}_{\alpha}, \mathrm{C}_{\mathrm{gr}}, \mathrm{Fe}_{3} \mathrm{C}\right)$. Microhardness measurements were done on OLC 45 steel samples processed by electric spark using electrodes $(\Phi=2 \mathrm{~mm})$ made of sintered carbides WCo8 and Ti15Co8 [6].

\begin{tabular}{|c|c|c|c|c|c|c|}
\hline No & $\begin{array}{c}2 \Theta_{\mathrm{i}} \\
{[\mathrm{deg}]}\end{array}$ & $\begin{array}{c}\Theta_{\mathrm{i}} \\
{[\mathrm{deg}]}\end{array}$ & $\begin{array}{c}\mathrm{d}_{\mathrm{hkl}} \\
\text { computed }[\AA]\end{array}$ & $\begin{array}{c}\mathrm{d}_{\mathrm{hkl}} \text { gauge } \\
{[\AA]}\end{array}$ & hkl & Phase \\
\hline 1 & 18.00 & 9.00 & 2.270 & 2.270 & $(102)$ & $\mathrm{W}_{2} \mathrm{C}$ \\
\hline 2 & 20.25 & 10.12 & 2.020 & 2.010 & $\begin{array}{c}(111) ; \\
(101)\end{array}$ & $\mathrm{F}_{\alpha} ; \mathrm{C}_{\mathrm{gr}}$ \\
\hline 3 & 33.50 & 16.75 & 1.233 & 1.232 & $\begin{array}{c}(102) ; \\
(140)\end{array}$ & $\begin{array}{c}\mathrm{W}_{2} \mathrm{C}+ \\
\mathrm{Fe}_{3} \mathrm{C}\end{array}$ \\
\hline 4 & 35.60 & 17.80 & 1.161 & 1.160 & $(233)$ & $\mathrm{Fe}_{3} \mathrm{C}$ \\
\hline 5 & 39.50 & 19.75 & 1.051 & 1.070 & $(400)$ & $\mathrm{TiC}$ \\
\hline 6 & 41.20 & 20.60 & 1.009 & 1.002 & $(203)$ & $\mathrm{W}_{2} \mathrm{C}$ \\
\hline 7 & 44.25 & 22.13 & 0.943 & 0.941 & $(202)$ & $\mathrm{WC}$ \\
\hline 8 & 48.60 & 24.30 & 0.863 & 0.864 & $(212)$ & $\mathrm{TiC}$ \\
\hline
\end{tabular}

Tab. 2. The diffraction data from experiments 


\begin{tabular}{|c|c|c|c|c|}
\hline Sample & Steel & Type of the electrode & Work condition & $\begin{array}{c}\text { White layer microhardness } \\
{\left[\mathrm{daN} / \mathbf{m m}^{2}\right]}\end{array}$ \\
\hline \multirow[t]{2}{*}{$\mathrm{A}^{*}$} & \multirow{10}{*}{ OLC 45} & WCo8 & \multirow[t]{2}{*}{1} & - \\
\hline & & Ti15Co6 & & - \\
\hline \multirow[t]{2}{*}{ B } & & WCo8 & \multirow[t]{2}{*}{2} & 1640 \\
\hline & & Ti15Co6 & & 1540 \\
\hline \multirow[t]{2}{*}{$\mathrm{C}$} & & WCo8 & \multirow[t]{2}{*}{3} & 1640 \\
\hline & & Ti15Co6 & & 1590 \\
\hline \multirow[t]{2}{*}{$\mathrm{D}$} & & WCo8 & \multirow[t]{2}{*}{4} & 1670 \\
\hline & & Ti15Co6 & & 1590 \\
\hline \multirow[t]{2}{*}{ E } & & WCo8 & \multirow[t]{2}{*}{5} & 1670 \\
\hline & & Ti15Co6 & & 1594 \\
\hline
\end{tabular}

Tab. 3. Microhardness measurements on OLC 45 *At 1 working condition the white layer formed is very thin. Determination of microhardness involves changing measurement conditions, the determination is not conclusive

From the analysis presented we shown as changing the white layer hardness is not significantly influenced by working conditionsbut appear a slight influence of electrode material used. Sparking with WCo8 electrode lead to hardness values in layer higher than with electrode Ti15Co6 [1].

For track the influence of basic material on the superficial layer microhardnessI made a second series of experiments were accomplished on OLC 45, RP3, 205 Cr115 samples steel.

The sample surfaces $15 \times 20 \times 5 \mathrm{~mm}$ were fine restricted and then processed by electric spark using electrodes $(\Phi=2 \mathrm{~mm})$ made of sintered carbides WCo8 [2]. The impulse discharge regimes were: the $3^{\text {rd }}$ regime with $\mathrm{I}_{\mathrm{SC}}=1.3 \mathrm{~A}$ and the $4^{\text {rd }}$ regime with $\mathrm{I}_{\mathrm{SC}}=1.8 \mathrm{~A}$ at a discharge energy $\mathrm{W}_{\mathrm{i}}=2.1-3.4 \mathrm{~J}$, impulse duration of approximately $9 \cdot 10^{-4} \mathrm{~s}$ and electrode vibrating amplitude of $0.3 \mathrm{~mm}$. Processing $1 \mathrm{~cm}^{2}$ of the sample's surface was completed in $45 \mathrm{~s}$. Before and after sparking the sample masses were determined. After sparking, the roughness of the treated surface, thickness of the deposited white layer and of the diffusion substrate and the $\mathrm{MHV}_{0.1}$ micro hardness were measured.

\begin{tabular}{|c|c|c|c|c|}
\hline No. & Steel & $\begin{array}{c}\text { Work } \\
\text { condition }\end{array}$ & $\begin{array}{c}\text { Type of the } \\
\text { electrode }\end{array}$ & $\begin{array}{c}\text { Microhardness on } \\
\text { white layer MHV } \\
\mathbf{5 0}\left[\mathbf{d a N} / \mathbf{m m}^{2} \text { ] }\right.\end{array}$ \\
\hline 1 & OLC45 & 4 & WCo8 & 1665 \\
\hline 2 & Rp3 & 4 & WCo8 & 1660 \\
\hline 3 & $205 \mathrm{Cr} 115$ & 4 & WCo8 & 1720 \\
\hline
\end{tabular}

Tab. 4.Microhardness on white layer

The results of measuring the geometrical parameters, mass increase, steel samples, in delivery state (a) and after final treatment (b) by spark processing in the $3^{\text {rd }}$ working regime, with hard electrode made of sintered carbides (WCo8), are given in Table 5.

A study of the wear behavior of the layers is performed on samples of OLC 45 white deposited layer, using an AMSLER apparatus.Kinematic diagram of an Amsler apparatus is shown in Figure 1.

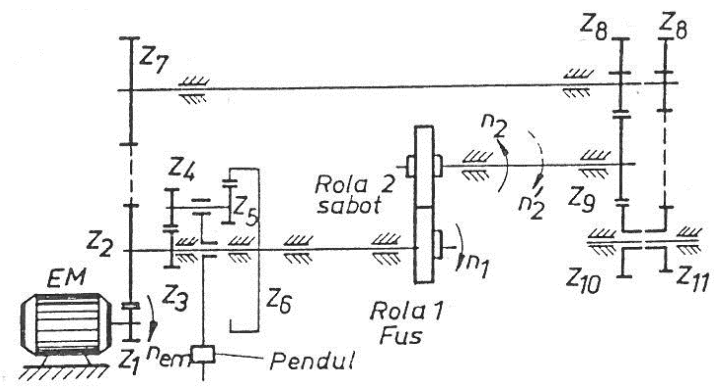

Fig. 1. Kinematic diagram of an Amsler apparatus

Samples used in the experiments have a configuration that depends on the type of couplings that use

Rotating supporting pin is purpose made from OLC 45 steel. It is on hardened steel and his Rockwell hardness is 45 .

The "shoe" samples from normalized OLC 45 steel where processed through superficial treatment on the surface of inner curvature. The superficial treatment through impulse electrical discharge was made with the ELITRON 22 A equipment at three working conditions. The electrodes using to electrical sparking are WCo8 and Ti15Co6.

Supporting pin - shoe assembly for wear test is shown in figure 2 . Wear resistance capacity is estimated by mass loss at $1000 \mathrm{~m}$ run depending on contact pressure. Mass changes were determined by weighing with analytical balance for both shoe and the supporting pin [7].

Tests were performed under the following conditions: working speed $\mathrm{v}=0.5 \mathrm{~m} / \mathrm{s}$, contact pressure $\mathrm{p}=1.5 ; 2.5$; $3.5 ; 4.0 \mathrm{MPa}$, trial time $\mathrm{t}=600 \mathrm{~s}$, running time $\mathrm{t}=800 \mathrm{~s}$ at $\mathrm{p}=1.0 \mathrm{MPa}$.

\begin{tabular}{|c|c|c|c|c|c|c|c|c|}
\hline \multirow[t]{2}{*}{ No. } & \multirow[t]{2}{*}{ Steel } & \multirow{2}{*}{$\begin{array}{l}\text { Treatment } \\
\text { state }\end{array}$} & \multirow{2}{*}{$\begin{array}{l}\text { Mass } \\
\text { Variation [g] }\end{array}$} & \multicolumn{2}{|c|}{ Layer thickness $[\mu \mathrm{m}]$} & \multicolumn{3}{|c|}{ Microhardness [daN/mm $\left.{ }^{2}\right]$} \\
\hline & & & & White & Diffusion & White & Diffusion & Basis \\
\hline \multirow{2}{*}{1.} & \multirow{2}{*}{ OLC 45} & $\mathrm{a}$ & 0.0058 & 40 & $45-48$ & 1660 & 890 & 342 \\
\hline & & $\mathrm{b}$ & 0.0048 & 41 & $43-50$ & 1658 & 650 & 680 \\
\hline \multirow[t]{2}{*}{2.} & \multirow[t]{2}{*}{ Rp3 } & $\mathrm{a}$ & 0.0069 & 41 & $44-50$ & 1662 & 700 & 420 \\
\hline & & $\mathrm{b}$ & 0.0031 & 40 & $45-55$ & 1650 & 670 & 685 \\
\hline \multirow[t]{2}{*}{3.} & \multirow[t]{2}{*}{$205 \mathrm{Cr} 115$} & $\mathrm{a}$ & 0.0060 & 41 & $54-62$ & 1665 & 990 & 640 \\
\hline & & $\mathrm{b}$ & 0.0059 & 43 & $60-65$ & 1670 & 930 & 985 \\
\hline
\end{tabular}

Tab. 5. Geometrical parameters, mass increase and microhardness of the obtained layers 

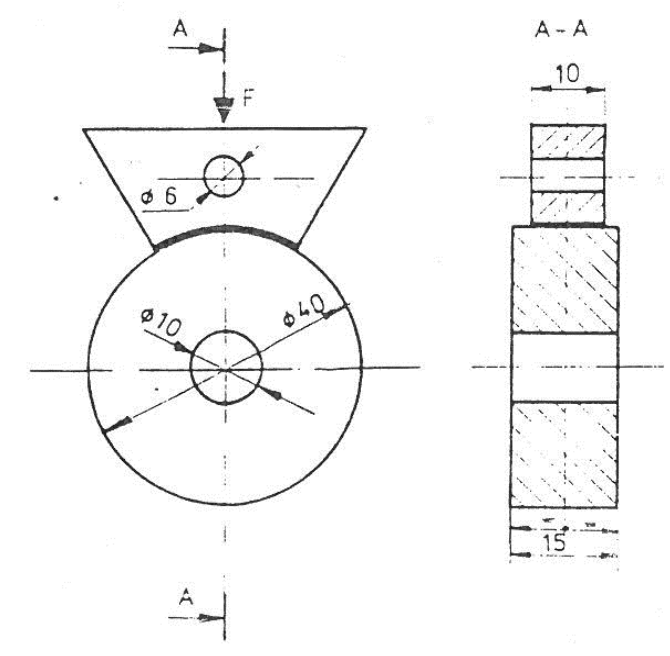

Fig. 2. Supporting pin - shoe assembly for wear test

The wear behavior of the hardened and unhardened coupons is listed in Table 6 .

\begin{tabular}{|c|c|c|}
\hline \multirow{2}{*}{$\mathbf{S}[\mathbf{m}]$} & \multicolumn{2}{|c|}{$\boldsymbol{\Delta} \mathbf{\Delta}$} \\
\cline { 2 - 3 } & 110 & $\mathbf{B}$ \\
\hline 125 & 150 & - \\
\hline 250 & 200 & - \\
\hline 500 & 360 & 30 \\
\hline 1000 & 580 & 36 \\
\hline 2000 & 810 & 45 \\
\hline 4000 & 1080 & 58 \\
\hline 6000 & 1390 & 70 \\
\hline 8000 & & 98 \\
\hline
\end{tabular}

Tab. 6. Mass $\operatorname{loss}(\Delta \mathrm{m})$ dependence on the abrasion length (S) after abrasion testing. Obs. A - sample untreated superficially B - sample treated by electric spark

\section{CONCLUSION}

The method used is simple and not expensive. The method is based on the material transfer effect from electrode to the surface of the treated piece during the electrical discharge in the gaseous environment between electrode and piece.

Using of optimal working regimes will lead to achieving some very good quality coatings

The type of coating depends on the electrode speed over the surface of the sample a well.

Superficial processing using electrical sparking is a typical discharging through multiple impulses and during a very short time. In essence, during the time of discharging a cathode erosion is produced and there is a material transfer on the processed surface.

A bigger distance between the electrodes leads to a high quantity of energy in the discharging channel, and to a decrease of the energy transmitted to electrodes. As a consequence, there is a decrease of erosion, so the material transfer between the electrodes is decreased.

Microhardness on layer is greater than on basic structure and enhanced values are obtained using the tungsten carbide electrodes.

Sparking with WCo8 electrode lead to hardness values in layer higher than with electrode Ti15Co6.
The thickness of the deposited layer can be as high as $100 \mu \mathrm{m}$.

The wear behavior of the layers is very good.

\section{ACKNOWLEDGEMENTS}

Several of the ideas presented in the paper are the result of the models developed in the framework of the scientific research study 'Development of computer assisted marine structures', Emil Oanta, Cornel Panait, Ghiorghe Batrinca, Alexandru Pescaru, Alexandra Nita, Feiza Memet, which is a component of the RoNoMar project, 2010, sponsor of this paper.

Ideas regarding the computer based instruments in applied elasticity are the result of the models developed in the framework of the MIEC2010 bilateral Ro-Md research project, Oanta, E., Panait, C., Lepadatu, L., Tamas, R., Constantinescu, M., Odagescu, I., Tamas, I., Batrinca, G., Nistor, C., Marina, V., Iliadi, G., Sontea, V., Marina, V., Balan, V. (2010-2012), "Mathematical Models for Inter-Domain Approaches with Applications in Engineering and Economy", MIEC2010 - Bilateral Romania - Moldavia Scientific Research Project, under the supervision of the National Authority for Scientific Research (ANCS), Romania.

That is the follow-up of the ID1223 scientific research project: Oanta, E., Panait, C., Nicolescu, B., Dinu, S., Pescaru, A., Nita, A., Gavrila, G., (2007-2010), "Computer Aided Advanced Studies in Applied Elasticity from an Interdisciplinary Perspective", under the supervision of the National University Research Council (CNCSIS), Romania.

\section{REFERENCES}

[1] Barhalescu, M. (2007).Researches regarding the obtaining and structural analysis on corrosion resistant thin superficial layers, Ph. D Thesis, Jassy, Romania

[2] Barhalescu, M.; Oanta, E.; Sabau, A.; Dumitrache, L. (2009). Internal sress in superficial layers on carbon steels, Annals of $D A A A M$ for 2011 \& Proceedings of the $22^{\text {nd }}$ International DAAAM Symposium, ISBN 978-3-901509-83-4, ISSN 1726-9679, pp 0845-0846, Branko Katalinic (Ed.), Published by DAAAM International, Vienna, Austria 2011

[3] Barankova, H.; Bardos, L.; Berg, S. (1996). Surface and Coating Technology, No. 94-95

[4] Chatterjee, S.K. (2008). Crystallography and the World of Symmetry, Springer, ISBN: 978-3-540-69898-2, Berlin

[5] Ladd. M.F.C. \& Palmer. R.A. (1985). Structure determination by $X$ ray Crystallography, Plenum Press, ISBN: 0306368444, New York

[6] Morton, P. H.; Bell, T. (1990). Les procedes technologique des surfaces appliqués au titan, Traitment Thermique, nr. 241, Paris

[7] Pauleau, Y. (1994). Materials and Procesesfor Surface and Interface Engineering, Kluwer Academic Publ., ISBN: 978-07923-3458-3, London 